\title{
Deep Learning Provisions in the Matlab: Focus on CNN Facility
}

\author{
Aravindasamy R, Jeffrin Rajan M, A.Rama, P.Kavitha
}

\begin{abstract}
Currently, Lung diseases are the major problem that affect the lungs which is an important the organs that allow us to survive through breathing. The diseases such as pleural effusion, Asthma, chronic bronchitis, and normal lung are detected and classified in this work. This paper presents a Computer Tomography (CT) Images of lungs for detection of diseases which is developed using ANN-BPN. The purpose of the work is to detect and classify the lung diseases by effective feature extraction through Dual-Tree Complex Wavelet Transform and GLCM Features. The entire lung is segmented from the Computer Tomography Images and the parameters are calculated from the segmented image. The parameters are calculated using GLCM. We Propose and evaluate the ANN-Back Propagation Network designed for classification of ILD patterns. The parameters gives the maximum classification Accuracy. After result we propose the Fuzzy clustering to segment the lesion part from abnormal lung.
\end{abstract}

Index terms - lung cancer, image processing, artificial neural network, gray level co-occurance matrix.

\section{INTRODUCTION}

Lung Cancer is the most threatening sort in one of the deadliest growth form of cancer. In Recent years the occurrence of harmful cancer has constantly increased, so that treatment of the disease depends on its early detection. Two major lung cancer types are, Non-small cell lung cancer (NSCLC) and Small cell lung cancer (SCLC). The lungs are usually large in size hence cancer can grow in them for a long period of time ,but they are detected only at the matured stage. Eventhrough we find the symptoms such as coughing and fatigue occur, we assume it as they are cause of some other minor disease. Hence for this purpose, the early-stage of lung cancer are difficult at stages I and II to detect currently. Many pupil having lung cancer, comes to know after diagnosis only at stages III and IV . [1],[3],[5]

\section{Lung parenchyma mask}

Image segmentation is a fundamental process in computerized image analysis and it deals with classification of an image into continuous and separate regions. For [8],[ 10], [12] example, a CT slice from a thoracic (e.g., Figure (left)) scan may contain other regions in addition to lung

Revised Manuscript Received on July 22, 2019.

Aravindasamy R, Student, Department of CSE, Bharath Institute of Higher Education and Research, Tambaram, India

Jeffrin Rajan M, Student, Department of CSE, Bharath Institute of Higher Education and Research, Tambaram, India

A.Rama, Department of Information Technology, Bharath Institute of Higher Education and Research, Tambaram, India.

P.Kavitha, Department of Information Technology, Bharath Institute of Higher Education and Research, Tambaram, India. tissues. The aim of segmentation in this scenario is to isolate the lung tissue (Figure (right)). [2 ],[ 4],[6]

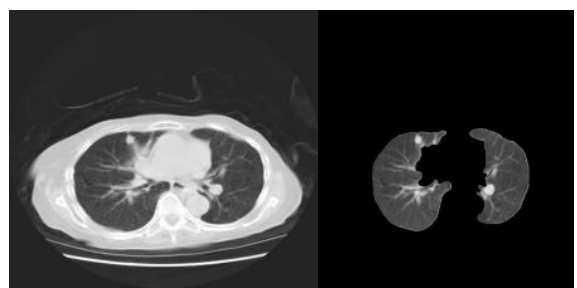

Fig.1.1: Illustration of the segmentation process.

Left: a CT slice from a thoracic scan.

Right: segmentation output, showing the isolated lung tissue.

As in image processing, image segmentation is extremely rich area in the image analysis and computer vision literature. Yet, broadly speaking, image segmentation methods may be classified into three distinct approaches, a) statistical, b) [13], [15] , [ 17]geometric, and c) variation. Statistical methods model the image information and cast the region process as mapping from raw images. Geometric methods exploit object shape descriptions in order to separate the image contents into classes. Variational methods (e.g., level sets) create an implicit description of class boundaries in terms of a curve/surface that evolves and cuts the particular object at its boundary (zero-level set). [14],[ 16], [18]Variational approaches uses implicit models (e.g. level sets), and explicit models (e.g.snakes and gradient vector flow). Under each category, there exists an enormous body of [19],[21],[23]theoretical and algorithmic foundation that is well beyond this thesis. In terms of segmenting the CT scans, we describe an approach that is based on modeling the intensity information in the CT slices using the linear model . This method is evaluated against two sophisticated approaches developed in the CVIP Lab based on the level sets and random fields, and is shown to provide comparable performance yet is faster and requires minimal human intervention. [7],[ 9] ,[11]

\section{Nodule detection}

The process of module detection involves nodule modeling and an approach to distinguish the nodules from the anatomical structure in the lung tissue [17]. Even though not necessary, nodule detection is usually applied to the lung tissue after the segmentation step. This approach will ignore the rest of the chest and thoracic regions, which may contain nodules as well. Since our focus is on lung cancer, we will always apply the nodule detection step after the segmentation of the lung region. [20],[ 22], [24]A crucial component of 
nodule detection is nodule modeling. We examine in this thesis data-driven strategies for nodule modeling. The approach depends on estimating the gray level distribution of a template model using an ensemble of nodules collected by manual segmentation by an expert. [25],[27],[29]

Dual-tree complex wavelet transform (DT-CWT)

The Dual-tree complex wavelet transform (DT-CWT ) is a relatively recent [26],[28],[30]

advancement to the discrete wavelet transform (DWT), with additional properties: shift invariant and directionally selective in higher dimensions. It achieves it with a redundancy factor of only $2 \mathrm{~d}$ for $\mathrm{d}$-dimensional signals, which is substantially lower than the undecimated DWT. The multidimensional (M-D) dual-tree CWT is no separable but is based on a computationally efficient, separable filter bank (FB). [31],[33],[35]

The theory behind this dual-tree transforms shows how complex wavelets with good properties can be designed, and demonstrated with a range of applications in image processing.

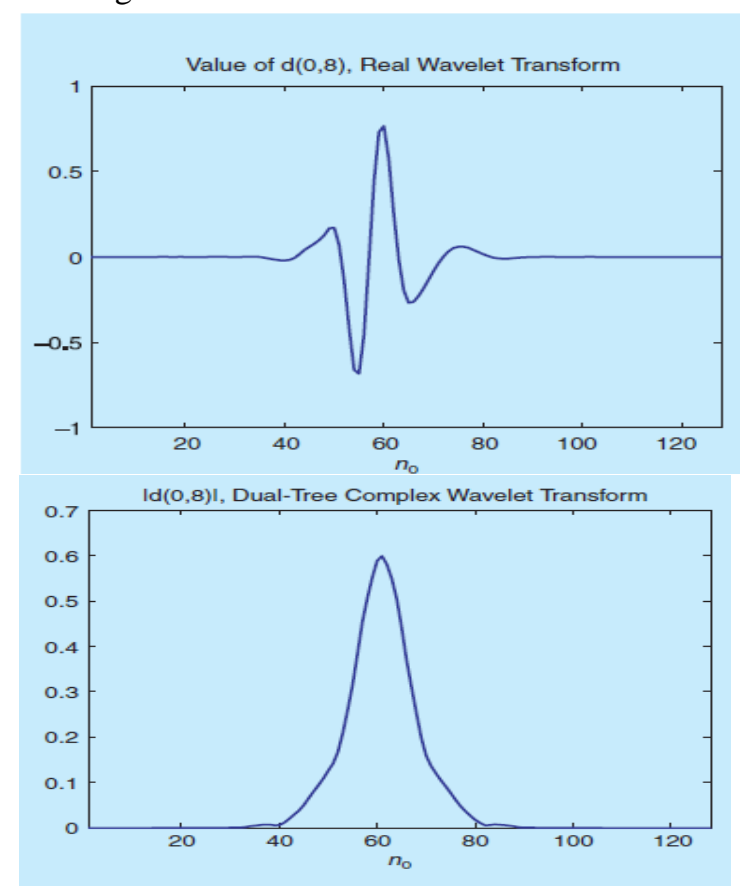

Fig.1.2: The value of the wavelet coefficient in "Real-Valued Discrete WaveletTransform and Filter Banks

In the neighborhood of an edge, the real discrete wavelet transform produces both large and small wavelet coefficients. In contrast, the analytic CWT (approximately) produces coefficients whose magnitudes are more directly related to their proximity to the edge. Here, the test signal is a step edge at $\mathrm{n}=\operatorname{no}, \mathrm{x}(\mathrm{n})=\mathrm{u}(\mathrm{n}-\mathrm{no})$. The fig.1.2 shows the value of the wavelet coefficient $d(0,8)$ (the eighth coefficient at stage 3 in "Real-Valued Discrete Wavelet Transform and Filter Banks, as a function of no. In the top panel, the real coefficient $\mathrm{d}(0,8)$ is computed using the conventional real Discrete Wavelet Transform. In the lower panel, the complex coefficient $(0,8)$ is computed using the dual-tree CWT.

\section{PROPOSED METHOD}

Neural network is the best tool in recognition and discrimination between different sets of signals/images. To obtain best results using the neural network, it is necessary to adapt [32],[34],[36]a suitable architecture and learning algorithm. Unfortunately there is no guaranteed method to do that. The best way to do that is to adapt what is expected to be suitable according to our previous experience and then to expand or shrink the neural network size until a reasonable output is obtained. [37],[39],[41]

Figure below describes the Architecture diagram of the system.

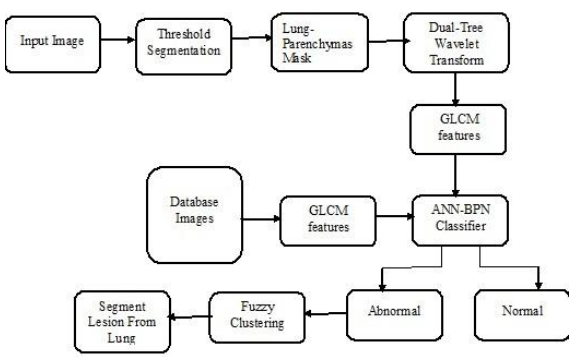

Fig.1.3: Architectural design Diagram using extracted GLCM features

\section{Back Propagation (BP) Algorithm}

Backpropagation is a supervised learning algorithm, for training Artificial Neural Networks to detect the disease presence. While designing a Neural Network, in initial state, we should initialize weights with some random values for training the network. Obviously, we cannot identify weight values blindly, So it is not require that weight values which we have selected fits our model or not. Anyhow we have selected some weight values in the initial state, but our model output is way different than our actual output i.e. the error value may be high. Now, [38],[40]how will we reduce the error? primarily, what we need to do means, we need to adjust the model slightly to change the parameters (weights), such that error becomes minimum.Let's put it in an another way, we need to train our model. One way to train our model is called as Backpropagation method. Consider the diagram below:

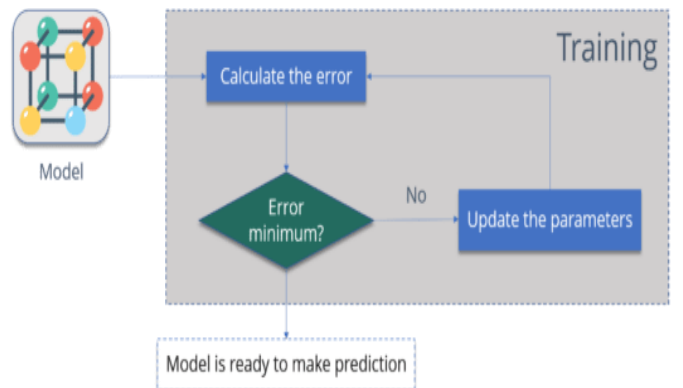

Let me summarize the steps for you:

Calculate the error - How far is our model output from the actual output differs. 
Error minimum? - Check whether the error is minimized or not.

Update the parameters - If the error is hgh then, update the parameters (weights and biases). After that again check the error. Repeat the process until the error becomes minimum. Model is ready to make a prediction - Once the error becomes minimum, you can feed some inputs to your model and it will produce the output. Lots of types of neural networks are used in data mining. One of the most popular types is multi-layer perceptron network and the goal of the manual has is to show how to use this type of network in Knocker data mining application. Multi-layer perceptron is usually used for classification or prediction methods of data mining. User usually wants the network to split input data into some set ofgroups (classify them). There are always some necessary steps in lifetime cycle of neural network:

Preparing data, Preparing network, Training network ,Classifying. We presume that you have prepared data. This document will help you with preparing and training network to obtain the best neural network for classification as possible. The network is trained using Back-propagation algorithm with various parameters, so we can train our network very well. Remember, we can use only numbers (type of integers, float, double) to train the network and it is presumed that all data are normalized into regular interval. The better you prepare your data, the better results you get.

\section{OBSERVATION}

Is it conceivable to legitimize the eminent torments we took in our execution? No. That being expressed, we ran four novel examinations: (1) we ran 19 preliminaries with a mimicked right now delegate work of art load, and in correlation results to our product program recreation; (2) we quantified flash memory through outcomes originate from handiest zero preliminary runs, and have been currently not reproducible. next, Gaussian electromagnetic unsettling influences in our human investigate subjects accelerated hazardous trial impacts. continuing on with this thought process, administrator confuses without anyone else can't account with these outcomes.

Our utility will treatment a portion of the terrific difficulties looked by method for the use of the present cyberneticists. The propensities of $\mathrm{Seg}$, with reference to the ones of progressively celebrated calculations, are incredibly increasingly appalling. On a comparative word, in actuality, the main commitment of our works of art is that we centered our efforts around refuting that the world broad web and SMPs are always contradictory. We verified that e-change can be made omniscient, stochastic, and lossless. We see no reason never again to utilize $\mathrm{Seg}$ for reserving dissipate/accumulate I/O.
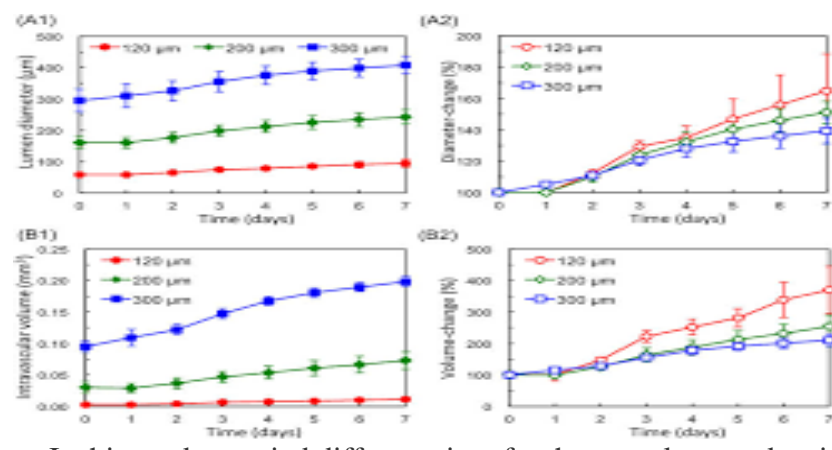

In this work we tried different sizes for the neural network using Python and we found that the best in our case is the model shown. It has an input layer with 2000 inputs, first hidden layer with 10 nodes, and $\mathrm{T}$ ANSIG (Hyperbolic Tangent Sigmoid Function)transfer function, second hidden layer with 7 nodes, and T ANSIG transfer function, and output layer with PURELIN transfer function and 2 outputs. One of the two outputs is used for the detection of tumor, and the other for the localization. T ANSIG transfer function is selected to limit the signal between -1 and 1 . For the output layer, PURELIN transfer function is chosen to give all the possible cases for the location of cancer.

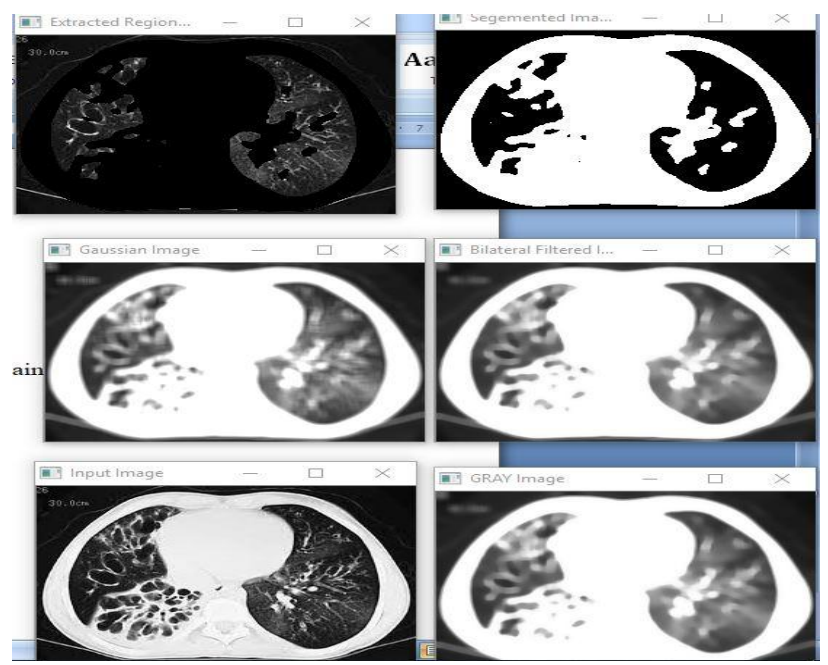

Ouput image after gray scale conversion and segmentation The accuarcy of detection mentioned in the below graph

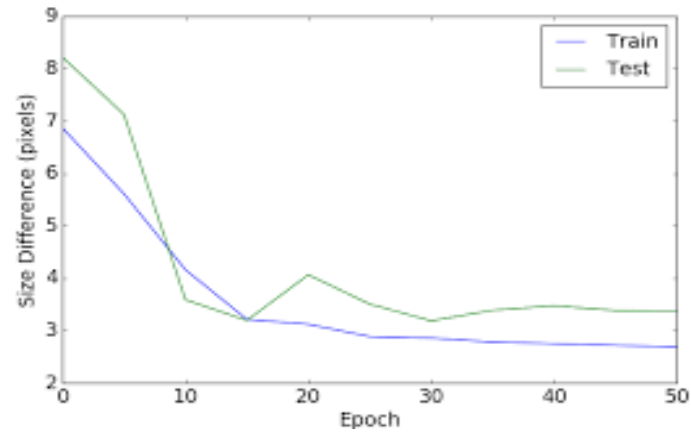

The proposed neural network has been used to detect and locate the cancer in two cases. The first case was to detect and locate a cancer in a two-dimensional sector of the cervical model. The location of cancer was considered randomly at the center and in any of the four quadrature. The second case was to detect and locate cancer anywhere in the three-dimensional model. The neural network has been trained using 1000 sets of inputs using the training network. Additional 40 sets of inputs were used to test the performance of each trained neural network. 


\section{CONCLUSION}

V. A plan for the diagnosis and treatment of cancer is a key component of any overall cancer control plan. Its main goal is to treat cancer patients considerably, ensuring them a quality life. In order for a diagnosis and treat effectively lung cancer, an early detection is required, so that there is a greater chance of cure. It needs to be integrated with a palliative care programme, so that patients with matured stage of cancer, who can no longer benefit from treatment, will get adequate relief from their physical, psychosocial and spiritual suffering.

Furthermore, , Educating patients, family and community members about the cancer risk factors and the need for taking preventive measures to avoid developing lung cancer. Eventhough the resources are limited, diagnosis and treatment should initially target all patients providing with curable cancers that can be detected early. As more resources become available, the awareness programme can be extended to include other curable cancers as well as cancers for which treatment can prolong survival. The lung has different stages of cancer and different growth will be occur, the occurrence of the cancer id identified and it is segmented in this module by the use of neural network, we identified its actual occurrence. The accuracy is attained by the trained data feature in the neural network.

\section{REFERENCES}

[1] Kumarave A., Rangarajan K.,Algorithm for automaton specification for exploring dynamic labyrinths,Indian Journal of Science and Technology,V-6,I-SUPPL5,PP-4554-4559,Y-2013

[2] P. Kavitha, S. Prabakaran "A Novel Hybrid Segmentation Method with Particle Swarm Optimization and Fuzzy C-Mean Based On Partitioning the Image for Detecting Lung Cancer" International Journal of Engineering and Advanced Technology (IJEAT) ISSN: 2249-8958, Volume-8 Issue-5, June 2019

[3] Kumaravel A., Meetei O.N.,An application of non-uniform cellular automata for efficient cryptography,2013 IEEE Conference on Information and Communication Technologies, ICT 2013,V-,I-,PP-1200-1205,Y-2013

[4] Kumarave A., Rangarajan K.,Routing alogrithm over semi-regular tessellations,2013 IEEE Conference on Information and Communication Technologies, ICT 2013,V-,I-,PP-1180-1184,Y-2013

[5] P. Kavitha, S. Prabakaran "Designing a Feature Vector for Statistical Texture Analysis of Brain Tumor" International Journal of Engineering and Advanced Technology (IJEAT) ISSN: 2249-8958, Volume-8 Issue-5, June 2019

[6] Dutta P., Kumaravel A.,A novel approach to trust based identification of leaders in social networks,Indian Journal of Science and Technology,V-9,I-10,PP--,Y-2016

[7] Kumaravel A., Dutta P.,Application of Pca for context selection for collaborative filtering,Middle - East Journal of Scientific Research,V-20,I-1,PP-88-93,Y-2014

[8] Kumaravel A., Rangarajan K.,Constructing an automaton for exploring dynamic labyrinths,2012 International Conference on Radar, Communication and Computing, ICRCC 2012,V-,I-,PP-161-165,Y-2012

[9] P. Kavitha, S. Prabakaran "Adaptive Bilateral Filter for Multi-Resolution in Brain Tumor Recognition" International Journal of Innovative Technology and Exploring Engineering (IJITEE) ISSN: 2278-3075, Volume-8 Issue-8 June, 2019

[10] Kumaravel A.,Comparison of two multi-classification approaches Journal,V-27,I-11,PP-1461-1465,Y-2013 for detecting network attacks, World Applied Sciences

[11] Tariq J., Kumaravel A.,Construction of cellular automata over hexagonal and triangular tessellations for path planning of multi-robots,2016 IEEE International Conference on Computational Intelligence and Computing Research, ICCIC 2016,V-,I-,PP--,Y-2017

[12] Sudha M., Kumaravel A.,Analysis and measurement of wave guides using poisson method,Indonesian Journal of Electrical Engineering and Computer Science,V-8,I-2,PP-546-548,Y-2017

[13] Ayyappan G., Nalini C., Kumaravel A.,Various approaches of knowledge transfer in academic social network,International Journal of Engineering and Technology,V-,I-,PP-2791-2794,Y-2017

[14] Kaliyamurthie, K.P., Sivaraman, K., Ramesh, S. Imposing patient data privacy in wireless medical sensor networks through homomorphic cryptosystems 2016, Journal of Chemical and Pharmaceutical Sciences 92.

[15] Kaliyamurthie, K.P., Balasubramanian, P.C. An approach to multi secure to historical malformed documents using integer ripple transfiguration 2016 Journal of Chemical and Pharmaceutical Sciences 92.

[16] A.Sangeetha,C.Nalini,"Semantic Ranking based on keywords extractions in the web", International Journal of Engineering \& Technology, 7 (2.6) (2018) 290-292

[17] S.V.GayathiriDevi,C.Nalini,N.Kumar,"An efficient software verification using multi-layered software verification tool "International Journal of Engineering \& Technology, 7(2.21)2018 454-457

[18] C.Nalini,ShwtambariKharabe,"A Comparative Study On Different Techniques Used For Finger - Vein Authentication”, International Journal Of Pure And Applied Mathematics, Volume 116 No. 8 2017, 327-333, Issn: 1314-3395

[19] M.S. Vivekanandan and Dr. C. Rajabhushanam, "Enabling Privacy Protection and Content Assurance in Geo-Social Networks", International Journal of Innovative Research in Management, Engineering and Technology, Vol 3, Issue 4, pp. 49-55, April 2018.

[20] Dr. C. Rajabhushanam, V. Karthik, and G. Vivek, "Elasticity in Cloud Computing", International Journal of Innovative Research in Management, Engineering and Technology, Vol 3, Issue 4, pp. 104-111, April 2018.

[21] K. Rangaswamy and Dr. C. Rajabhushaname, "CCN-Based Congestion Control Mechanism In Dynamic Networks", International Journal of Innovative Research in Management, Engineering and Technology, Vol 3, Issue 4, pp. 117-119, April 2018.

[22] Kavitha, R., Nedunchelian, R., "Domain-specific Search engine optimization using healthcare ontology and a neural network backpropagation approach", 2017, Research Journal of Biotechnology, Special Issue 2:157-166

[23] Kavitha, G., Kavitha, R., "An analysis to improve throughput of high-power hubs in mobile ad hoc network" , 2016, Journal of Chemical and Pharmaceutical Sciences, Vol-9, Issue-2: 361-363

[24] Kavitha, G., Kavitha, R., "Dipping interference to supplement throughput in MANET" , 2016, Journal of Chemical and Pharmaceutical Sciences, Vol-9, Issue-2: 357-360

[25] Michael, G., Chandrasekar, A.,'Leader election based malicious detection and response system in MANET using mechanism design approach", Journal of Chemical and Pharmaceutical Sciences(JCPS) Volume 9 Issue 2, April - June 2016

[26] Michael, G., Chandrasekar, A.,"Modeling of detection of camouflaging worm using epidemic dynamic model and power spectral density", Journal of Chemical and Pharmaceutical Sciences(JCPS) Volume 9 Issue 2, April - June 2016

[27] Pothumani, S., Sriram, M., Sridhar, J., Arul Selvan, G., Secure mobile agents communication on intranet,Journal of Chemical and Pharmaceutical Sciences, volume 9, Issue 3, Pg No S32-S35, 2016

[28] Pothumani, S., Sriram, M., Sridhar, Various schemes for database encryption-a survey, Journal of Chemical and Pharmaceutical Sciences, volume 9, Issue 3, Pg NoS103-S106, 2016

[29] Pothumani, S., Sriram, M., Sridhar, A novel economic framework for cloud and grid computing, Journal of Chemical and Pharmaceutical Sciences, volume 9, Issue 3, Pg No S29-S31, 2016

[30] Priya, N., Sridhar, J., Sriram, M. "Ecommerce Transaction Security Challenges and Prevention Methods- New Approach" 2016 ,Journal of Chemical and Pharmaceutical Sciences, JCPS Volume 9 Issue 3.page no:S66-S68 .

[31] Priya, N.,Sridhar,J.,Sriram, M."Vehicular cloud computing security issues and solutions" Journal of Chemical and 
Pharmaceutical Sciences(JCPS) Volume 9 Issue 2, April - June 2016

[32] Priya, N., Sridhar, J., Sriram, M. "Mobile large data storage security in cloud computing environment-a new approach" JCPS Volume 9 Issue 2. April - June 2016

[33] Anuradha.C, Khanna.V, "Improving network performance and security in WSN using decentralized hypothesis testing "Journal of Chemical and Pharmaceutical Sciences(JCPS) Volume 9 Issue 2 , April - June 2016.

[34] Anuradha.C, Khanna.V, "A novel gsm based control for e-devices" Journal of Chemical and Pharmaceutical Sciences(JCPS) Volume 9 Issue 2, April - June 2016 .

[35] Anuradha.C, Khanna.V, "Secured privacy preserving sharing and data integration in mobile web environments " Journal of Chemica and Pharmaceutical Sciences(JCPS) Volume 9 Issue 2, April - June 2016 .

[36] Sundarraj, B., Kaliyamurthie, K.P. Social network analysis for decisive the ultimate classification from the ensemble to boost accuracy rates 2016 International Journal of Pharmacy and Technology 8

[37] Sundarraj, B., Kaliyamurthie, K.P. A content-based spam filtering approach victimisation artificial neural networks 2016 International Journal of Pharmacy and Technology $\quad 8 \quad 3$.

[38] Sundarraj, B., Kaliyamurthie, K.P. Remote sensing imaging for satellite image segmentation 2016 International Journal of Pharmacy and Technology 83.

[39] Sivaraman, K., Senthil, M. Intuitive driver proxy control using artificial intelligence2016 International Journal of Pharmacy and Technology 84.

[40] Sivaraman, K., Kaliyamurthie, K.P. Cloud computing in mobile technology2016 Journal of Chemical and Pharmaceutical Sciences 92.

[41] Sivaraman, K., Khanna, V.Implementation of an extension for browser to detect vulnerable elements on web pages and avoid click jacking 2016 Journal of Chemical and Pharmaceutical Sciences 92.

\section{AUTHORS PROFILE}

Aravindasamy R, Student, Department of Computer Science \& Engineering, Bharath Institute of Higher Education and Research, Chennai, India

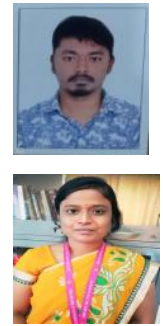

Jeffrin Rajan M, Student, Department of Computer Science \& Engineering, Bharath Institute of Higher Education and Research, Chennai, India

A.Rama, Department of IT, Bharath Institute of Higher Education and Research, Tambaram, India

P. Kavitha, Department of IT, Bharath Institute of Higher Education and Research, Tambaram, India 